\title{
Integration in Engineering Education: A Trial Run
}

\author{
http://dx.doi.org/10.3991/ijep.v3i3.2250 \\ M.Fikret Ercan \\ Singapore Polytechnic, Singapore
}

\begin{abstract}
The need for integrating engineering, science and various other disciplines in the engineering curriculum has long been the interest of engineering educators. An inherent problem is that many components of the engineering curriculum even within the same discipline remain separate and it is hoped that these concepts will all amalgamate in students mind when they graduate. At present, there are numerous initiatives presented in literature for exposing students to an integrated curriculum. In our institution, initiatives for such curricular change are underway. However, a trial run was necessary to establish learning and educational goals and to identify potential implementation difficulties earlier. This paper presents such pilot initiative which involved students and lecturers of different disciplines.
\end{abstract}

Index Terms-Integration; Engineering education; Curriculum design

\section{INTRODUCTION}

The notion of integration has been widely discussed in engineering education literature [1] [2] [3], and there are various definitions [3]. In this paper integration is perceived as not only making connections across scientific, engineering and various other disciplines, but also acquiring personal, interpersonal skills. In other words, we are concerned with holistic development of an individual together with his/her engineering skills. Authors in [2] describe the rationale for integrated curriculum design based on practical and pedagogical point of view and they present effective models for integrated curriculum design. It is important to note that time and resources are limited to cover all the advances that has been made in technology in any given curriculum. It is also becoming imperative for students to establish the link between math, science, and engineering at a very early stage in their study. Authors in [4] propose hands on activities and integration throughout the curriculum where students acquire necessary knowledge just in time. This imbues new graduates to acquire a set of personal and interpersonal skills such as thinking across a variety of disciplines, linking theory and practice, synthesizing and analyzing and so on [4].

The initiatives for remaking engineering education in our institution have been put in place recently and integration plays a vital role. Here, we are firstly concerned with making connections across various disciplines so that the context of engineering becomes more sophisticated and multidisciplinary. Any engineering field is now becoming increasingly dependent on other disciplines such as biology, medicine, physics, chemistry, design, and business. However, traditional engineering curriculums are highly focused and stand alone. Normally our students will be exposed to other disciplines only if they enroll in a multidisciplinary project in their final year. Furthermore, work environment that they will end up is cutting-edge and very dynamic. Graduates have to adapt to technical, organizational, cultural, intellectual and social changes. Furthermore, as innovation becomes the key differentiator in various industries [5] [6], it is important to inculcate the notion of design in our students so that they can develop innovative products and services rather than making incremental advances to them. Considering the needs of modern engineering graduates in Singapore, our institution adopted and implemented CDIO pedagogy since early 2007 and adapted 'design thinking' approach recently for conceiving user-centered innovative products and services [7][8]. The objective of adopting design thinking was more than making students innovators or more creative. As discussed in [9], skills attributed with good designers such as dealing with uncertainty, working in teams, making decisions, seeing the bigger picture are all aligned with our pedagogical aims. Considering these factors, our intended curriculum design aims redesigning of entire diploma program and teaching methodology which evolved around the following strategic points:

- Integrate various disciplines and introduce design thinking in every aspects of students' learning.

- Employ project based, hands on activities as an instrument to achieve pedagogical goals.

- Adopt a studio based teaching environment rather than lecture theaters and classrooms.

Our primary objectives in enhancing students' skills can be briefly defined as follows:

- Autonomy. This is a lifelong learning skill. It has various interpretations and definitions in literature. Here, it is interpreted as students' capability of decision making and determining his/her self-learning which in turn benefits them with better engagement, personal satisfaction and learning.

- Maker culture. The institution, being a polytechnic, primarily responds to the needs of local industry which is seeking engineers with hands on skills who can fit into work force rapidly. Hence introducing our students to design thinking and getting them involved into project work from the very beginning of their study, we try to give an understanding of what engineers do.

- Integration. As mentioned earlier, this is one of the key elements in our curricular change with the intention that our graduates will have a greater under- 
standing of engineering and how it is interlinked with other disciplines.

- Communication. Ideas are communicated in engineering and design in many ways ranging from equations to technical drawings, from sketches to presentations. Modern engineers need to use all means of communication effectively.

\section{PILOT RUN}

In order to evaluate the ideas mentioned above we have conducted a pilot run involving 20 students, who are in their second year, from two different disciplines: electrical and mechanical engineering. The program also involved lecturers from various disciplines including math, chemical and life sciences, electrical engineering, mechanical engineering, and design. It was planned as a workshop with a four-week duration.

\section{A. The project}

One of the key aspects in integrating various disciplines is to find a suitable theme or project [8]. In this program, faculty agreed upon bio mimicry which is basically deriving solutions to problems inspired from nature. As illustrated in Figure 1, many disciplines intersect in such a theme. The challenge given to the students was to propose a 'nature inspired cooling system for better living environment'. All the participants can easily relate to this problem since air-conditioning is the biggest energy drainer for buildings in tropical Singapore.

\section{B. The role of the faculty}

One of the challenges of designing an integrated curriculum is the isolation of disciplines from one another. Even the physical distance between different departments, in wide campuses like ours, may discourage development of an integrated curriculum. Faculty may perceive it as an invaluable but demanding task. It is very likely that views of faculty on various aspects of the program will also vary. For example, for a controlling type faculty, being supportive of students' autonomy may not be so imperative. It is therefore important that the teaching team is well informed of the rationale behind such curriculum design. During the delivery of the course, there may be two or more faculty members need to be present in the studio. This, apart from being a challenge for scheduling and planning, requires faculty members being comfortable with each other.

\section{Details of the program}

The overall structure of the program is composed of integrated engineering, science, design, and project work sessions. As shown in Figure 2, design was a supporting element throughout the program where students also produced a project demonstrating CDIO attributes. Given below is a brief description of these sessions.

\section{1) Design Studio:}

The design studio primarily instilled students with design thinking tools and principles such as:

- Introduction to design process: Journaling and documentation.

- Instruments of analysis: Visual research, storyboarding and data visualization.

- War room technique and POEMS.

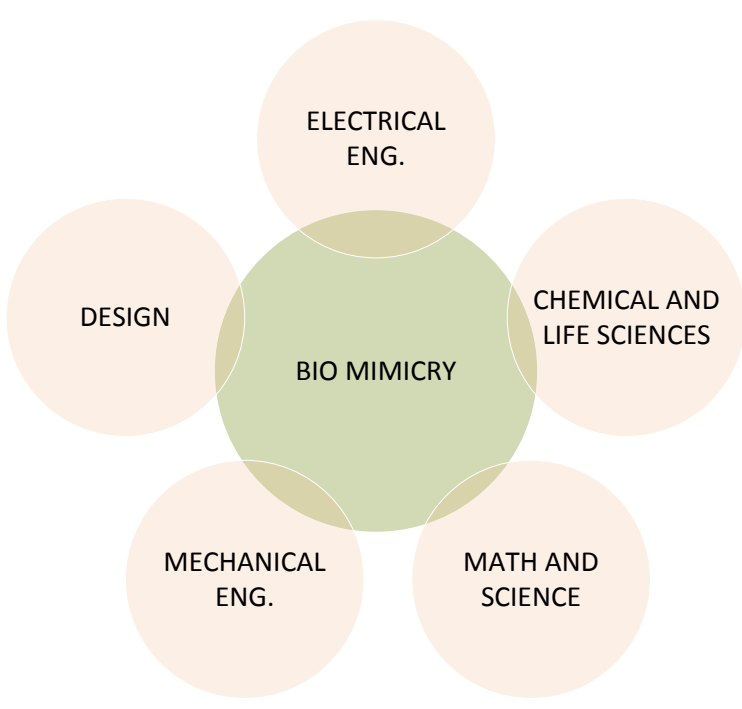

Figure 1. Project anchoring to various disciplines

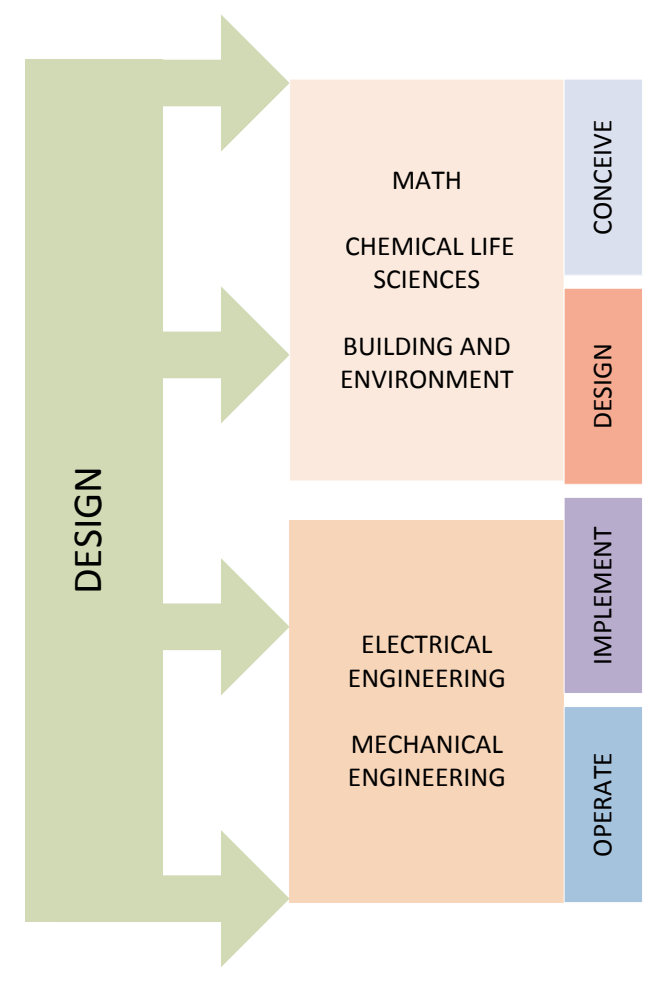

Figure 2. Overall structure of the program

- Understanding Users: Ethnography, interview, collection of images and data

- Ideation methods and techniques.

- Design and ideas development: In-depth research into specific areas of interest and SCAMPER technique.

- Sketch models of the ideas. Presentation comprising design developmental images, diagrams, sketches, annotations and reflections.

- Prototype production.

Figure 3 shows snapshots from design sessions where students work in groups to improve their design ideas. In contrast to the typical engineering project, in this exercise they are not given specifications or a project description. 

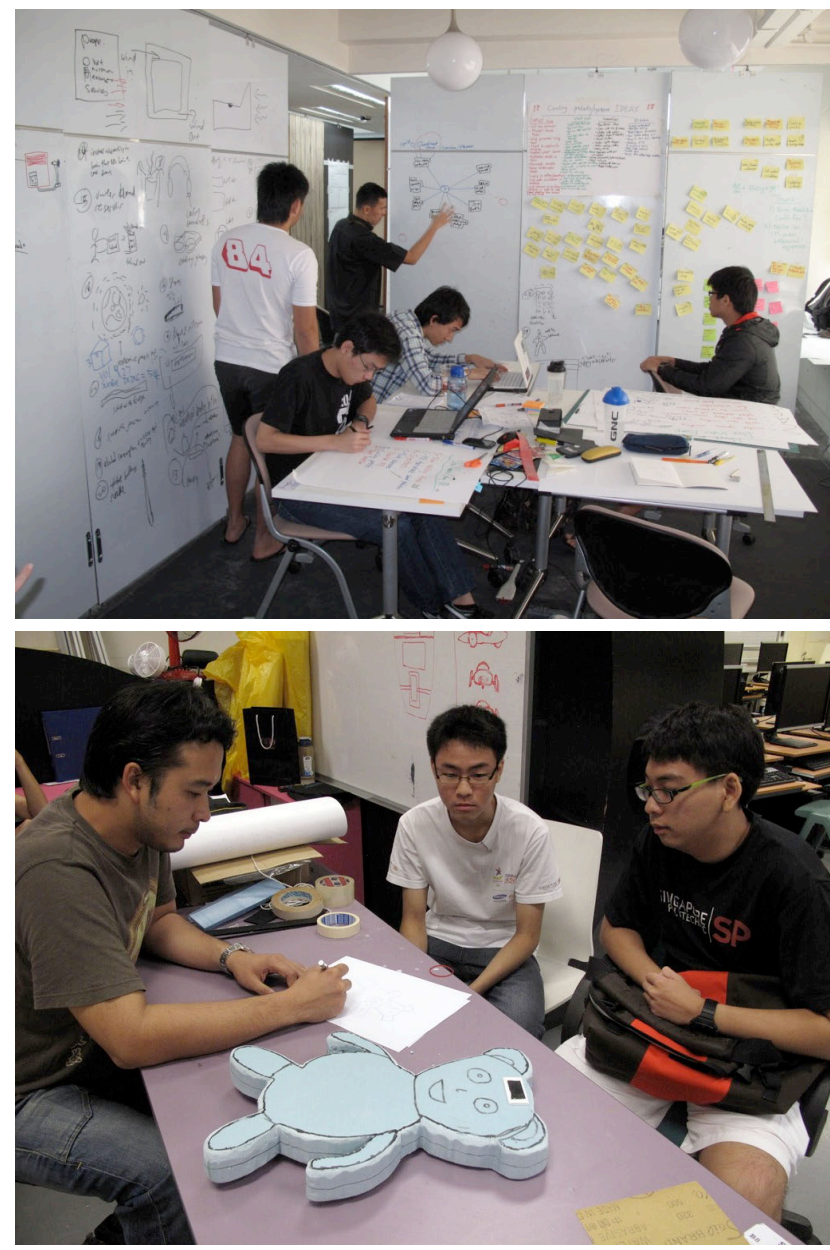

Figure 3. Design process

Hence, student did significant amount of observation, design journaling, ethnography studies before refining their project ideas. Nature being their primary sources of inspiration, some interesting ideas came from a study of wasp nests, insulation capability of otters, properties of water and humidity and so on. Given that students had a short period time, they were not able to implement a large scale project. However they were able to design and conduct experiments to prove their ideas and develop prototypes and some working models to visualize it.

\section{2) Engineering Studio I:}

This module is prepared collectively by electrical and mechanical engineering faculty using electric fans and air conditioner to showcase integration of these two disciplines. A typical cooling system is made of various mechanical and electrical components such as electric motors, sensors, microcontrollers etc. In this session, learning experience is primarily contextual and students were introduced to the following topics:

- The concept of circular motion.

- The concept of balancing and vibration of rotating systems.

- Balancing of rotating masses.

- Sensors and their operation principles.

- Bridge circuit, sensor readings and calibration.

Students understood the above concepts experimenting with a desk fan. They analyzed circular motion in theory
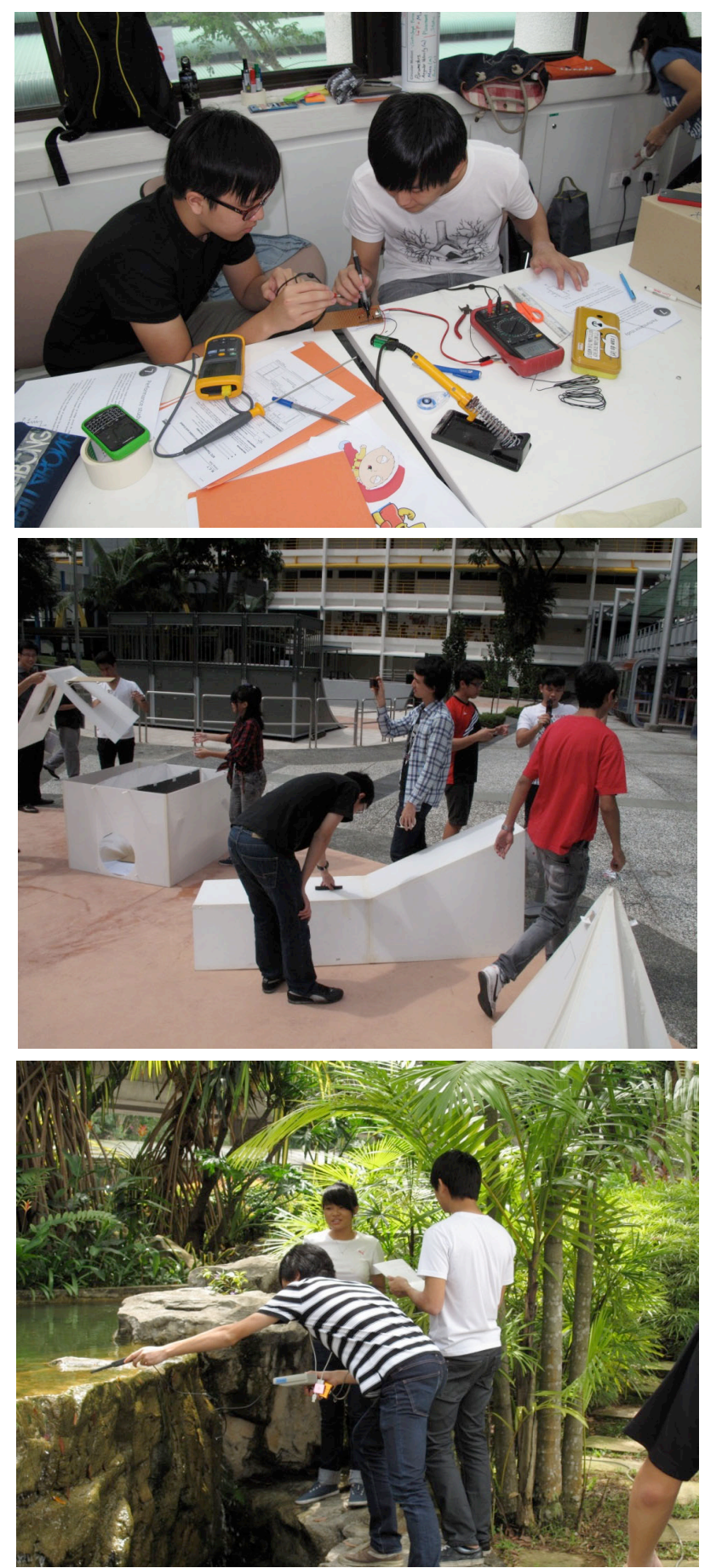

Figure 4. Students actively taking part in the learning process

and experimented with it. They understood how imbalances in rotating blades can cause vibration and instability. Furthermore, students developed and calibrated an electronic thermometer by using simple bridge circuit, thermistor and a digital multimeter. Figure 4 shows snap shots from engineering studio sessions where students designed their own experiments exploiting what they had learned.

\section{3) Engineering Studio II:}

This is another integrated module developed by faculty from building and environment, chemical and life science and maths. Students were introduced to the concept of humidification using a real world example "How does 
Cheonggyecheon stream cool down Seoul temperature by $3.6^{\circ} \mathrm{C}$ ?"

The following learning areas and case studies were explored:

- Humidity, relative and saturation humidity.

- Adiabatic cooling line, dry bulb temperature and wet bulb temperature.

- The relationship between humidity and air temperature.

- The connections between humidity and adiabatic cooling line.

- The relations of water quality and the cooling effect due to humidification process.

- Appling the humidity and adiabatic cooling line concept to the cooling of nature.

- Mathematical techniques to solve Fick's 2nd Law problem associated to humidification.

- Modeling and simulation of the various factors that can affect the cooling rate/temperature drop related to this case study.

Students self-explored the concepts related to humidification and verified their own understanding through simple experiments. They also designed an experiment mimicking Cheonggyecheon stream. During the process of consolidating their experimental results, they were introduced to the idea of modeling and simulation.

\section{Communication skills}

The importance of communication skills and the need for improving them for engineering students has long been a debated issue. Communication is an important skill for engineering students not only for their learning but also for their future career [10]. Typically, good communication skills are perceived as good written and oral communication skills. However, for modern engineers, communication needs expands to good listening, visual, interdisciplinary and intercultural skills as well [10]. Emotional intelligence is another key skill that needs to be embedded in future engineers. Empathy skills are not only required for handling interpersonal relations with colleagues and others but is also a key component for successful design process.

Throughout the pilot run students were exposed to various forms of communication while making presentations to large audiences, writing reports, preparing sketches and journals, posters, prototypes and so on. Figure 5 and 6 show snap shots of various forms of communication modes students used. For the capstone project they observed and interviewed users during design stage which instilled empathy skills. It was an unusual form to start a project for engineering students though they found it rewarding.

\section{E. Assesment}

In this scheme, learning takes place as a group and assessing a student's learning as well as contribution to group work is a tedious task. Moreover, our objective is to assess the entire learning process rather than the final project work. Therefore throughout this learning journey, a number of tools are used for the assessment. Assessment for group work, individual work and final project work spread to the duration of the course. In each design studio
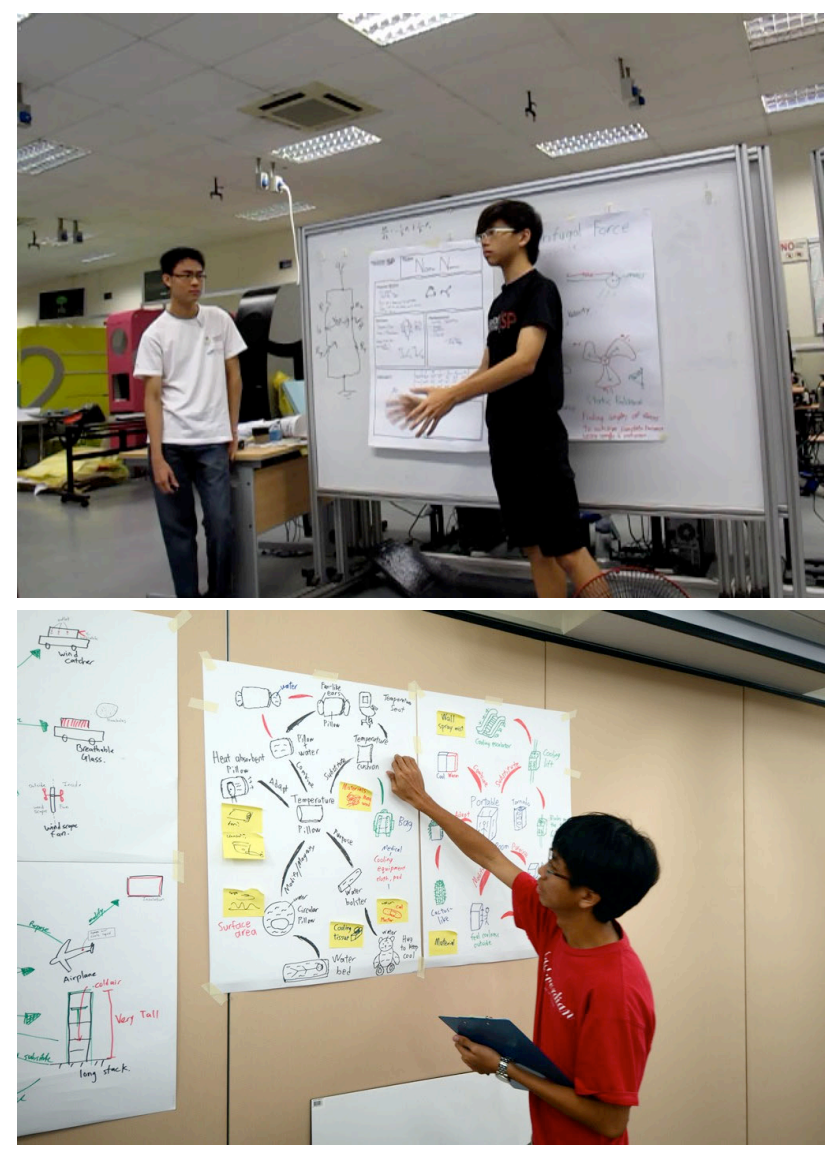

Figure 5. Using oral and visual communication skills

or engineering studio session a group work is delivered such as a protype or presentation of solution to a problem etc. Individual assessment means were assignments and research journals. Learning journals are typically used to echo students learning process in project based education. We use research journal where students documented their research, observations, design process, and their conclusions and reflections. The final project work co-assessed by all the lecturers involved in this exercise as well as peer assessed by fellow students.

\section{DISCUSSIONS}

Organizing an integrated curriculum where various faculty and disciplines collaborate is a challenging task. Based on our experience, we are able to deduce the following key points when planning such a program:

- Design thinking, teamwork, student autonomy should be knitted into the program.

- Students should be given opportunities to utilize all forms of communication.

- Having a studio like learning space is essential.

- Teaching staff should have background or training in planning integrated curriculums. In our institution, the teaching team was trained in design thinking via a series of workshops. Furthermore, the teaching team, involved in curriculum change, also attended workshops like I2E2 Summer Institute organized by Olin College [11].

A feedback session was held with students after the program. Overall, it was well received by the students. 
Some of the interesting comments from students are listed below:

"Interesting, not typical, and I get to do things on my own; not just listening to lecturers talking all the time."

"I learned that I can integrate nature with products."

"Social aspect must be of my interest"

"Previously I don't like to draw, but this course makes me draw and draw. Now I feel drawing is quite fun." tive."

"This program makes us think from different perspec-

"In the beginning, I though it's crazy to think of impossible ideas. Now I don't think so"

Students also feedback that their confidence level in handling stressful situations, presentations and communication, putting ideas on paper, and thinking "out of the box" improved as they went through this learning experience.

On the other hand, it was surprising to find out that students had many reservations when it comes to open ended problems and dealing with uncertainty. They also indicated that studio based experience was less efficient in acquiring knowledge. This is perhaps had to do with their earlier learning habits and it needs to be investigated further.

\section{SUMmary AND Future Plans}

This paper presented our initiatives for an integrated engineering curriculum design and a pilot program that has been conducted to foresee implementation issues. A major challenge is to choose a right theme, project or problem where integration can naturally be part of the equation. Furthermore, dealing with a problem that students are familiar with in their daily life motivates them naturally and their sense of worth was evident during their presentations. Although this project started as a pilot program to test out our curriculum plans, we have soon realized that similar programs can be embedded into our existing course in the form of workshops or extracurricular activities. Similar programs can also be a quick remedy for institutions trying to adapt to the needs of modern engineering education when making drastic changes in their curriculum may not be so straightforward.

\section{ACKNOWLEDGMENT}

The author is grateful to colleagues Noel Kristian, Chong Chi Wei, Soh Ying Ying, Wendy Leck, James Lee and Sudhir K. Jajharia in preparation and implementation of this pilot run. Finally, author is particularly indebted to students of electrical and mechanical engineering who took part in this program and gave their feedback.

\section{REFERENCES}

[1] B. Linder and W. C. Flowers, "Integrating Engineering Science and Design:A Definition and Discussion" Journal of Engineering Education, vol. 17, pp. 436-439, 2001

[2] K. Edström, S. Gunnarsson and G. Gustafsson, "Integrated Curriculum Design", in Rethinking Engineering Education, pp.77101, Springer-Verlag, 2007. http://dx.doi.org/10.1007/978-0-38738290-6_4

[3] J. E. Froyd and M. W. Ohland, "Integrated Engineering Curricula", Journal of Engineering Education, vol. 94, pp. 147-164,2005. http://dx.doi.org/10.1002/j.2168-9830.2005.tb00835.x
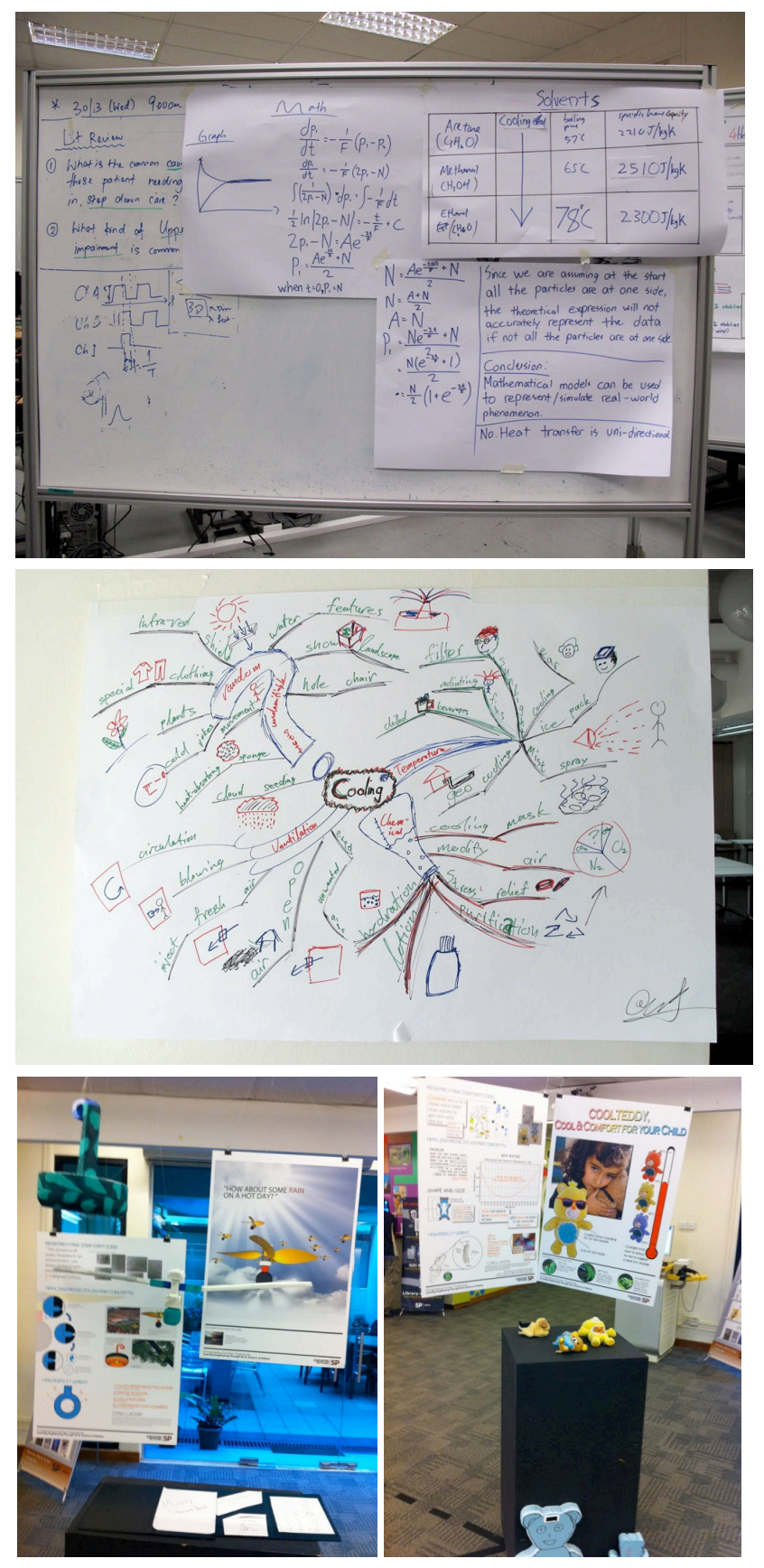

Figure 6. Various forms of visual communication used during the pilot run

[4] J. Bordogna, E. Fromm and E. W. Ernst, "Engineering Education: Innovation Through Integration", Journal of Engineering Education, vol. 82, pp. 3-8, 1993. http://dx.doi.org/10.1002/j.21689830.1993.tb00065.x

[5] T. Brown, "Design Thinking", Harward Bussiness Review, pp.1$10,2008$.

[6] V. Kumar, A Process for Practicing Design Innovation, Journal of Business Strategy, Vol. 30, No. 2/3, pp. 91-100, 2009. http://dx.doi.org/10.1108/02756660910942517

[7] Soh, K.F, “An Observational Study of Infusing Design Thinking into the CDIO framework", Proceedings of 7th International CDIO Conference, June 20 - 23, 2011.

[8] K..F. Soh, "CDIO as a Meaningful Framework for Final Year Aerospace Projects", Proceedings of 4th ISATE symposium, 2010.

[9] C. L. Dym, A. M. Agogino, O. Eris, D. D. Frey and L. J. Leifer "Engineering Design Thinking, Teaching, and Learning", Journal 
of Engineering Education, vol. 94, pp. 103-120, 2005. http://dx.doi.org/10.1002/j.2168-9830.2005.tb00832.x

[10] M. J. Riemer, "Communication Skills for the 21st Century Engineer", Global Journal of Engineering. Education, Vol.11, No.1, pp. 89-100, 2007.

[11] http://i2e2.olin.edu

\section{AUTHOR}

M.Fikret Ercan is with the School of Electrical and Electronic Engineering, Singapore Polytechnic, Singapore (mfercan@sp.edu.sg).

Submitted 31 August 2012. Published as re-submitted by the authors 26 June 2013. 